\title{
MÉTODOS PARA A REMOÇÃO DE SULFETO DE HIDROGÊNIO DE EFLUENTES GASOSOS APLICÁVEIS A REATORES ANAERÓBIOS
}

\author{
Mateus da Silva Szarblewski $i^{29}$ \\ Rosana de Cassia de Souza Schneider ${ }^{30}$ \\ Enio Leandro Machado ${ }^{31}$
}

\begin{abstract}
RESUMO
Neste trabalho de revisão foram avaliados os principais métodos utilizados para o tratamento de emissões atmosféricas contendo $\mathrm{H}_{2} \mathrm{~S}$, descrevendo suas vantagens e desvantagens. Buscou-se encontrar tecnologias mais adequadas para o tratamento do $\mathrm{H}_{2} \mathrm{~S}$ emitido por reatores anaeróbios. Uma análise qualitativa dos vários métodos indicou que a utilização de absorção química com solução redox de ferro (III) reúne o maior conjunto de vantagens para o tratamento do $\mathrm{H}_{2} \mathrm{~S}$ emitido por este tipo de reatores, como a possibilidade da reutilização da solução de ferro evitando gastos com reposição de reagentes e geração de um coproduto (enxofre elementar) que pode ser comercializado ou retornado ao meio ambiente em forma de insumos agrícolas.
\end{abstract}

Palavras-chave: Sulfeto de hidrogênio. Tratamento de gases. Reatores anaeróbios.

\begin{abstract}
In this review it was assessed the main methods used for the treatment of $\mathrm{H}_{2} \mathrm{~S}$ in atmospheric emission, describing its advantages and disadvantages. It was attempted to find more appropriate technologies for the treatment of $\mathrm{H}_{2} \mathrm{~S}$ emitted by anaerobic reactors. A qualitative analysis of the several methods stated that the use of chemical absorption with iron redox solution (III) gathers the largest number of advantages for the treatment of $\mathrm{H}_{2} \mathrm{~S}$ issued by these kind reactor, as the possibility of reusing the iron solution avoiding spending on reagents replacement and also generating a byproduct (elemental sulfur) which can be sold or returned to the environment in shape of agricultural inputs.
\end{abstract}

Keywords: Hydrogen sulfide. Gas emissions treatment. Anaerobic reactors.

\section{INTRODUÇÃO}

A poluição atmosférica vem preocupando cada vez mais a sociedade, pois afeta diretamente a qualidade de vida de cada um. Os sistemas, de transporte e produção de energia, envolvidos na agricultura e processos industriais são grandes responsáveis pelas formas de poluição atmosférica que provêm do homem.

29 Acadêmico do Sétimo Semestre do Curso de Química Industrial pela Universidade de Santa Cruz do Sul (UNISC). mateusilva91@hotmail.com. Bolsista (PIBIC/CNPQ).

30 Doutora em Química Vinculada ao Departamento de Química e Física da Universidade de Santa Cruz do Sul (UNISC). rosana@unisc.br

31 Doutor em Engenharia - Metalurgia Extrativa Vinculado ao Departamento de Química e Física da Universidade de Santa Cruz do Sul (UNISC). enio@unisc.br 
A alta gama de poluentes que são emitidos diariamente pode causar efeitos locais e imediatos, como maus odores, efeitos nocivos à saúde e também a formação de fumaça, ou problemas globais, como a destruição da camada de ozônio, a chuva ácida e o efeito estufa (TACLA, 2004).

A poluição atmosférica é gerada toda vez que uma forma de matéria ou energia libere no ar substâncias tóxicas ou em concentrações elevadas, que modificam o aspecto estético, composição, ou a forma do meio físico e tornam o ar impróprio ou ofensivo à saúde humana, causando também danos materiais à fauna e flora (CAMPOS, 2009; SEINFELD, 1975).

O impacto das substâncias poluentes na atmosfera depende da composição ou concentração das mesmas, bem como das condições climáticas na região de emissão (SCHIRMER, 2008).

Entre os principais agentes contaminantes encontrados na atmosfera está o sulfeto de hidrogênio $\left(\mathrm{H}_{2} \mathrm{~S}\right)$. Após sua liberação pela atividade microbiana natural ou por emissões antrópicas, esse gás é facilmente oxidado a dióxido de enxofre $\left(\mathrm{SO}_{2}\right)$ o qual é posteriormente convertido a ácido sulfúrico $\left(\mathrm{H}_{2} \mathrm{SO}_{4}\right)$, que retorna ao solo na forma de "chuva ácida" (ROCHA, 2007).

Sabe-se que dentre os processos industriais e urbanos que podem produzir sulfeto de hidrogênio estão: (i) tratamento de águas residuais; (ii) processamento de alimentos; (iii) refino de petróleo e gás natural; (iv) indústrias petroquímicas; (v) curtumes; (vi) fabricação de celulose e papel; (vii) e os processos de compostagem (SHAREEFDEEN, 2009; AROCA, 2007).

Segundo Aroca et al. (2007) emissões de sulfeto de hidrogênio por atividades industriais são a principal causa de corrosões e odores desagradáveis nos grandes centros urbanos.

Entre as fontes de emissão de sulfeto de hidrogênio estão os reatores de fluxo ascendente do tipo UASB (do inglês Upflow Anaerobic Sludge Blanket), que estão sendo muito utilizados para o tratamento de efluentes de grandes centros urbanos e indústrias. De acordo com Glória (2009) o tratamento de esgotos é feito por micro-organismos anaeróbios que convertem a matéria orgânica do efluente em gases como metano $\left(\mathrm{CH}_{4}\right)$ e dióxido de carbono $\left(\mathrm{CO}_{2}\right)$ e os sulfatos em sulfeto de hidrogênio $\left(\mathrm{H}_{2} \mathrm{~S}\right)$.

Em condições, geralmente anaeróbicas, os micro-organismos decompõem o enxofre orgânico encontrado nas proteínas dos seres vivos (aminoácidos, cisteína e metionina), transformando em sulfeto de hidrogênio (GARCIA JR, 1989).

Segundo Zaman e Chakma (1994), o sulfeto de hidrogênio é um recurso relativamente abundante, cujo potencial não vem sendo plenamente utilizado pela da indústria. É um gás, do qual dois produtos importantes, o hidrogênio e o enxofre, podem ser extraídos.

Com esta revisão busca-se identificar qualitativamente um processo de tratamento de gases que atenda os requisitos relatados por Chernicharo et al (2010), para o gerenciamento de emissões odorantes de Estações de Tratamento de Efluentes (ETEs), mais especialmente dos reatores anaeróbios. Em países em desenvolvimento os pontos críticos destacados pelos autores são: (i) custos operacionais, (ii) de construção, (iv) sustentabilidade e (v) simplicidade. 


\section{TOXICOLOGIA DO SULFETO DE HIDROGÊNIO}

De acordo com Mainier, Sandres e Tavares (2007) o gás sulfídrico é um gás incolor, solúvel em água e possui um cheiro característico de "ovo podre". É altamente tóxico aos seres humanos, porque se combina com o ferro do citocromo e outros compostos essenciais que contêm ferro na célula (SILVA, 2008).

Mills (1998) ressalta que o olfato humano pode detectar o gás sulfídrico em níveis de concentração de $0,13 \mathrm{ppm}\left(0,18 \mathrm{mg} \mathrm{m}^{-3}\right)$. Porém, se exposto a tempos prolongados, a sensibilidade oftálmica diminui tornando o olfato um detector imperfeito do $\mathrm{H}_{2} \mathrm{~S}$.

A exposição máxima permitida por períodos prolongados é de $10 \mathrm{ppm}$, sendo que 30 minutos de exposição a concentrações superiores de 300 ppm torna-se fatal (MAAT et al, 2004).

Os casos de intoxicação por $\mathrm{H}_{2} \mathrm{~S}$ são mais acentuados principalmente no setor industrial. Segundo Gregorakos et al. (1995), as autópsias realizadas em funcionários que morreram em um acidente envolvendo vazamento de sulfeto de hidrogênio revelaram que os corpos possuíam edemas pulmonares, miocardite, hemorragia na mucosa gástrica, além do cérebro e da parte posterior do intestino apresentar a cor esverdeada e alguns casos de ataque cardíaco.

\section{EMISSÕES DE SULFETO DE HIDROGÊNIO EM REATORES ANAERÓBIOS}

De acordo com Horikawa et al. (2004) processos anaeróbios tem sido utilizados com mais frequência para o tratamento de efluentes, pois provocam a eficiente degradação de compostos orgânicos na ausência de oxigênio molecular. Estes processos são basicamente biológicos e produzem como coproduto uma mistura de gases composta principalmente por metano $\left(\mathrm{CH}_{4}\right)$, dióxido de carbono $\left(\mathrm{CO}_{2}\right)$ e sulfeto de hidrogênio $\left(\mathrm{H}_{2} \mathrm{~S}\right)$.

Reatores UASB são os principais representantes da tecnologia de tratamento anaeróbio. São sistemas de tratamento baseados na rota natural de mineralização, e com o tempo, vão se tornar soluções de desenvolvimento sustentável, sendo que entre seus coprodutos, principalmente o metano possui grande potencial energético (CHERNICHARO et al., 2010).

Os reatores UASB são unidades utilizadas para tratar efluentes que contenham na sua maioria matéria orgânica em suspensão ou dissolvida. De acordo com Souza (2010) o tratamento ocorre por via de sucessivas conversões bioquímicas após os processos de dispersão e difusão que ocorrem na massa de micro-organismos presentes no lodo é que se dá a remoção da matéria orgânica (DQO ou DBO, isto é, carboidratos, proteínas, lipídios ou seus metabólitos)

A decomposição anaeróbia da fração proteica contida na matéria orgânica é a principal causa da geração de odores.

Relatos de Silva (2007) citam que dentre os impactos negativos do tratamento de esgotos, encontram-se a proliferação de odores ofensivos, um dos principais motivos de reclamações das ETEs, pois causam grande desconforto para a população dos arredores destas instalações.

Em um reator do tipo UASB o sulfeto de hidrogênio é formado pela redução do sulfato (sulfetogênese), na presença de matéria orgânica e condições específicas, segundo as equações de 1 a 3. 


$$
\begin{aligned}
& \mathrm{SO}_{4}{ }^{2-}{ }_{(a q)}+\text { matéria orgânica }{ }_{\text {(disolv./dispers.) }} \rightarrow \mathrm{S}^{2-}{ }_{(a q)}+\mathrm{H}_{2} \mathrm{O}_{(l)}+\mathrm{CO}_{2(g)} \\
& \mathrm{S}^{2-}{ }_{(a q)}+\mathrm{H}^{+}{ }_{(q q)} \rightarrow \mathrm{HS}_{(a q)}^{-} \text {[2] } \\
& \mathrm{HS}_{(a q)}{ }_{(a)}+\mathrm{H}_{(a q)}^{+} \rightarrow \mathrm{H}_{2} \mathrm{~S}_{(a q)}[3]
\end{aligned}
$$

O sulfato, presente no efluente a ser tratado, é utilizado como aceptor final de elétrons para as reações bioquímicas. Agrawal et al. (1997) reportam em seu trabalho que as concentrações de $\mathrm{H}_{2} \mathrm{~S}$ em reatores UASB pode ficar entre 0,11 e $0,39 \%$.

De acordo com os estudos de Glória (2009) a concentração de sulfeto de hidrogênio nas proximidades de reatores UASB pode ser de 0,2 a 5 ppm.

Souza (2010) descreve que os principais fatores de influência de emanações atmosféricos de $\mathrm{H}_{2} \mathrm{~S}$ são: (i) o $\mathrm{pH}$ e a temperatura; (ii) a taxa de geração e concentração do $\mathrm{H}_{2} \mathrm{~S}$; (iv) da turbulência e das taxas de ventilação da superfície do efluente no interior do reator; e (v) da área superficial do líquido exposta à atmosfera.

Estudos realizados por Souza (2010), em um reator UASB funcionando em condições específicas, revelaram que o balanço do enxofre estava distribuído nos seguintes percentuais: $75,1 \%$ do sulfeto estão solubilizados no efluente tratado; $16 \%$ estão retidos no lodo; e 1,3\% são emitidos junto ao biogás, nas condições que ele relatou.

\section{PROCESSOS DE TRATAMENTO DE SULFETO DE HIDROGÊNIO}

Em seu trabalho Zaman e Chakma (1995) se referem ao sulfeto de hidrogênio como uma potencial fonte para a geração de hidrogênio e enxofre elementar. $O$ interesse na utilização de sulfeto de hidrogênio como fonte de hidrogênio e enxofre tem se intensificado nos últimos anos por causa das seguintes razões: (i) perspectiva global de energia de hidrogênio e minimização de resíduos; (ii) a inevitável produção de sulfeto de hidrogênio a partir de plantas de gás, refinarias, metalúrgicas e em processos industriais anaeróbios, que vão desde tratamento de resíduos até sistemas industriais como o de Kraft da celulose, para a produção de papel; e (iii) problemas ambientais e sociais causados pela emissão de sulfeto de hidrogênio à atmosfera.

Existem várias medidas que podem ser tomadas para minimizar as emissões dos gases odorantes. Em um primeiro momento investigam-se mudanças no processo e equipamentos que possam refletir na redução de emissão do gás poluente. Nos casos onde não existem medidas para minimização dos efeitos dos gases odorantes, ou onde essas medidas não são eficientes, há a necessidade de se programar uma tecnologia de tratamento desses gases (SILVA, 2008; SCHIRMER, 2008).

Chernicharo et al. (2010) constataram que os métodos para o controle de gases odorantes em estações de tratamento de esgoto podem ser caracterizados como de natureza física, química e bioquímica. Para eles os processos químicos e físicos já vêm sendo desenvolvidos a mais tempo do que os processos biológicos.

Rocha (2007) sugere que os processos mais empregados para se reduzir a toxicidade e o odor proveniente de gases e vapores industriais são: adsorção, absorção (acompanhada ou não de reação química), combustão (incineração) e condensação. 
Para a seleção da tecnologia adequada devem-se levar em conta as condições de concentração, vazão e temperatura em que o gás residual é emitido, e a capacidade de tratamento requerida. Relacionando-se a questões financeiras o método deve ter baixo custo de instalação e operação (ROCHA et al. 2004).

De acordo com Martin (2008) existem muitas tecnologias disponíveis para remoção de sulfeto de hidrogênio, no entanto, é difícil de encontrar uma forma barata e com suficiente eficácia na remoção.

$\mathrm{Na}$ Tabela 1 estão representados os princípios e seus respectivos processos de tratamento do sulfeto de hidrogênio e emissões odoríferas.

No processo de Adsorção as moléculas dos líquidos, gases ou vapores (adsorvato) são retidas por forças físicas (adsorção física ou fisiossorção) ou químicas (adsorção química, quimiossorção) na superfície de um sólido (adsorvente). Para a estruturação deste sistema é necessário a confecção de uma coluna de recheio, ou de pratos perfurados, recoberta com o material adsorvente. A adsorção física, se comparada com a química, possuí uma fraca interação entre adsorvato e o adsorvente, o que faz com que esse processo necessite condições de resfriamento. Já a adsorção química, de maior interação entre adsorvato e adsorvente requer temperaturas altas para a regeneração do adsorvente sólido.

Tabela 1 - Princípios de tratamento de $\mathrm{H}_{2} \mathrm{~S}$ e seus respectivos sistemas.

\begin{tabular}{cl}
\hline Princípio & \multicolumn{1}{c}{ Tipos de plantas } \\
\hline \multirow{2}{*}{ Físico } & Adsorção: com o uso de adsorventes; \\
& Lavadores com água pura; \\
& Membranas seletivas; \\
& Separação criogênica. \\
\hline \multirow{3}{*}{ Químico } & Absorção com substâncias químicas; \\
& Oxidação térmica; \\
& Oxidação Catalítica; \\
& Ozonização. \\
\hline \multirow{3}{*}{ Biológico } & Biofiltro; \\
& Biopercolador; \\
& Biolavador; \\
& Tratamento com lodo ativado. \\
\hline
\end{tabular}

Fonte: Adaptado de Silva, 2008.

A absorção refere-se à transferência de um componente sólido (absorbato) presente em fase gasosa (gás de arraste) para um líquido (absorvente). No controle de poluição do ar, a absorção envolve a remoção de um contaminante gasoso de uma corrente gasosa por sua dissolução em um líquido (podendo este ser uma solução redox). A absorção é um processo de transferência de massa que se dá devido a uma diferença de concentração entre os meios presentes. Esta transferência ocorre até que continue havendo diferença de concentração nos meios envolvidos. Na absorção química o efluente gasoso é transferido para uma fase líquida de baixa volatilidade. É um sistema estruturado em colunas de recheio, de pratos ou de nebulização, requerendo um espaço consideradamente pequeno.

Para Gendel et al. (2009) o uso de soluções redox, compostas principalmente por $\mathrm{Fe}(\mathrm{III}) / \mathrm{Fe}(\mathrm{II})$, como forma de adsorção química de sulfeto de hidrogênio está se tornando uma técnica eficaz. Neste sistema utiliza-se uma solução oxidante de Fe(III) que é capaz de 
fazer a rápida oxidação do $\mathrm{H}_{2} \mathrm{~S}$ a enxofre elementar. Depois disso, o enxofre pode ser removido por filtração ou gravidade.

$\mathrm{Na}$ reação com o sulfeto de hidrogênio incorporado a fase aquosa (Equação 4), a solução de $\mathrm{Fe}(\mathrm{III})$ é reduzida a $\mathrm{Fe}$ (II) (Equação 5). O Fe(II) pode ser facilmente oxidado e regenerado no sistema (Equação 6). Essa oxidação pode ser realizada pelo contato direto da solução com o oxigênio atmosférico (FRARE et al. 2009), ou então, pela utilização de uma pilha eletrolítica, na qual pode ser obtido como coproduto o gás hidrogênio (MATTHÍASDÓTTIR, 2006).

$$
\begin{aligned}
& \text { Transferência de massa gás/líquido: } \mathrm{H}_{2} \mathrm{~S}_{(g)} \rightarrow \mathrm{H}_{2} \mathrm{~S}_{(a q)} \\
& \text { Absorção: } \mathrm{H}_{2} \mathrm{~S}_{(a q)}+2 \mathrm{FeCl}_{3(a q)} \rightarrow 2 \mathrm{HCl}_{(a q)}+2 \mathrm{FeCl}_{2(a q)}+\mathrm{S}_{(s)}^{\circ} \\
& \text { Oxidação: } \mathrm{O}_{2(a q)}+4 \mathrm{Fe}^{2+}{ }_{(a q)}+2 \mathrm{H}_{2} \mathrm{O}_{(l)} \rightarrow 4 \mathrm{Fe}^{3+}{ }_{(a q)}+4 \mathrm{OH}_{(a q)}^{-}
\end{aligned}
$$

Os seguintes fatores podem se incluírem como vantagem da degradação do sulfeto de hidrogênio por cloreto férrico: (i) elevada eficiência de remoção de $\mathrm{H}_{2} \mathrm{~S}$; (ii) seletividade na remoção do $\mathrm{H}_{2} \mathrm{~S}$, evitando-se gasto desnecessário de reagentes; (iii) as condições ambientes são favoráveis ao processo; (iv) a solução utilizada é facilmente regenerada; (v) e a absorção química do $\mathrm{H}_{2} \mathrm{~S}$ traz como produto final o enxofre elementar, produto estável, de fácil comercialização e que pode ser disposto em aterro industrial com menor potencial poluente (HORIKAWA et al., 2004; SOUZA, 2010).

Os métodos microbiológicos de remoção de gases de efeito estufa baseiam-se na capacidade que certas espécies de bactérias, fungos ou leveduras apresentam de degradar Compostos Orgânicos Voláteis (VOCs) e os Compostos Inorgânicos Voláteis (VICs), (OTTENGRAF et al., 1986).

Para o tratamento biológico de efluentes gasosos as três técnicas mais utilizadas são os biolavadores, biopercoladores e os biofiltros. Esses sistemas são compostos por espécies microbianas que degradam e incorporando poluentes orgânicos ou inorgânicos derivados das correntes gasosas, para formar produtos como água, dióxido de carbono e materiais necessários para a sua reprodução celular.

As bactérias são inoculadas em materiais suportes e, com o seu crescimento, formam uma espécie de biofilme que preenche a coluna de filtragem de gases. (LEDUC et al., 1994).

Estas bactérias utilizam a energia química obtida a partir da oxidação de compostos reduzidos de enxofre para o seu crescimento celular. Elas removem elétrons livres do enxofre inorgânico e os emprega para a redução do carbono inorgânico $\left(\mathrm{CO}_{2}\right)(\mathrm{SYED}$ et al., 2006).

Assim, nos reatores biológicos são necessárias duas etapas responsáveis pela deterioração dos gases odoríferos. A primeira é a transferência dos gases para um meio líquido ou para um biofilme, e segunda os gases são degradados pelos micro-organismos presentes no biofilme. Quando na presença de oxigênio as bactérias oxidam as espécies iônicas a substâncias sulfurosas não odoríferas (CABRAL e BELLI, 2002). 
$\mathrm{Na}$ Tabela 2 estão resumidas algumas das principais tecnologias empregadas para o tratamento do sulfeto de hidrogênio, ressaltando alguns de seus aspectos.

\begin{tabular}{|c|c|c|}
\hline Método & & \\
\hline \multirow{4}{*}{ ADSORÇÃO } & FUNDAMENTO & $\begin{array}{l}\text { Refere-se ao processo em que as moléculas de compostos orgânicos voláteis } \\
\text { entram em contato com a superfície de um adsorvente sólido e se ligam via } \\
\text { forças moleculares fracas (Van der Waals). } \\
\text { Existem vários meios de adsorção para a remoção de } \mathrm{H}_{2} \mathrm{~S} \text {, incluindo carvão } \\
\text { ativado, óxido de ferro, e sílica gel }\end{array}$ \\
\hline & VANTAGENS & $\begin{array}{l}\text { - Custos de capital moderados; } \\
\text { - Mecanicamente simples; } \\
\text { - Ocupam pequena área (devido à grande área de superfície dos adsorventes, } \\
\text { e baixo tempo de retenção do gás); } \\
\text { - Estável e de desempenho elevado e confiável; }\end{array}$ \\
\hline & DESVANTAGENS & $\begin{array}{l}\text { - Os poluentes são transferidos para uma nova fase ao invés de serem } \\
\text { destruídos; } \\
\text { - Custos operacionais muito elevados (substituição/regeneração do carvão } \\
\text { ativado); } \\
\text { - Gera corrente secundária de resíduo (carvão não regenerável); } \\
\text { - Não é seletivo. }\end{array}$ \\
\hline & REFERÊNCIAS & $\begin{array}{l}\text { FISCHER, } 2010 . \\
\text { KLINKENBIJL et al } 1999 \\
\text { LI, } 2008 .\end{array}$ \\
\hline \multirow{4}{*}{$\begin{array}{c}\text { SEPARAÇÃO POR } \\
\text { MEMBRANAS }\end{array}$} & FUNDAMENTO & $\begin{array}{l}\text { Baseia-se na diferença do tamanho de partícula ou afinidade que certas } \\
\text { moléculas possuem em relação a materiais poliméricos (permeação selectiva). } \\
\text { A força motriz do presente processo é uma diferença de pressão entre os } \\
\text { gases. A taxa de permeação é determinada pelo produto de um coeficiente de } \\
\text { solubilidade e um coeficiente de difusão. Moléculas menores são altamente } \\
\text { solúveis e permeam pela membrana mais rápido do que moléculas grandes }\end{array}$ \\
\hline & VANTAGENS & $\begin{array}{l}\text { - Baixo custo de manutenção (sem partes móveis) } \\
\text { - Baixas exigências de energia; } \\
\text { - Baixa implementação; } \\
\text { - Simples para ampliação; } \\
\text {-Tecnologia em desenvolvimento. }\end{array}$ \\
\hline & DESVANTAGENS & $\begin{array}{l}\text { - As membranas têm custo elevado; } \\
\text { - Membranas podem ser facilmente contaminadas por suspensões presentes } \\
\text { no gás a ser tratado; } \\
\text { - Alguns solventes podem degradar a membrana; }\end{array}$ \\
\hline & REFERÊNCIAS & $\begin{array}{l}\text { AMARAL, } 2009 \\
\text { REIJENGA et al., } 2008\end{array}$ \\
\hline \multirow[t]{4}{*}{ ALCANOLAMINA } & FUNDAMENTO & $\begin{array}{l}\text { É o processo comercial mais utilizado para a remoção de } \mathrm{H}_{2} \mathrm{~S} \text { e também } \mathrm{CO}_{2} \text {. } \\
\text { Neste, vários tipos de aminas (de caráter básico) podem ser utilizadas: a } \\
\text { monoetanolamina, dietanolamina, diglicolamina e metildietanolamina. Uma } \\
\text { solução de amina em baixa temperatura e alta pressão (condições que } \\
\text { favorecem a absorção dos componentes ácidos) é bombeada em } \\
\text { contracorrente com o gás contaminado. } \mathrm{O} \mathrm{H}_{2} \mathrm{~S} \text { é absorvido pela solução de } \\
\text { amina formando um complexo instável ácido-base solúvel e libera calor. } \mathrm{Na} \\
\text { etapa de regeneração, são utilizadas condições de alta temperatura e baixa } \\
\text { pressão para favorecer o sentido inverso da reação para liberar o } \mathrm{H}_{2} \mathrm{~S} \\
\text { absorvido. Após este processo, o } \mathrm{H}_{2} \mathrm{~S} \text { é geralmente incinerado. } \\
2 \mathrm{R}_{2} \mathrm{NH}_{(\mathrm{aq})}+\mathrm{H}_{2} \mathrm{~S}_{(\mathrm{g})} \leftrightarrow\left(\mathrm{R}_{2} \mathrm{NH}_{2} \mathrm{~S}_{(\mathrm{aq})}+\text { calor }\right. \\
\left(\mathrm{R}_{2} \mathrm{NH}_{2}\right)_{2} \mathrm{~S}_{(\mathrm{aq})}+\mathrm{H}_{2} \mathrm{~S}_{(\mathrm{g})} \leftrightarrow 2\left(\mathrm{R}_{2} \mathrm{NH}_{2}\right) \mathrm{HS}_{(\mathrm{aq})}+\text { calor }\end{array}$ \\
\hline & VANTAGENS & $\begin{array}{l}\text { - Alta eficiência na separação dos gases contaminantes; } \\
\text {-Recirculação no sistema da solução filtrante; }\end{array}$ \\
\hline & DESVANTAGENS & $\begin{array}{l}\text { - Somente separa, e não trata os poluentes da corrente gasosa, sendo } \\
\text { necessário ainda um destino adequado desses gases; } \\
\text { - Elevado gastos energéticos com operações térmicas e de bombeamento; } \\
\text { - Elevado custo de instalação; }\end{array}$ \\
\hline & REFERÊNCIAS & KOHL e RIESENFELD, 1985 \\
\hline
\end{tabular}


Continuação...

\begin{tabular}{|c|c|c|}
\hline & & $\begin{array}{l}\text { OPRIME, } 2001 \\
\text { ALIABAD e MIRZAEI, } 2009 \\
\end{array}$ \\
\hline \multirow{4}{*}{$\begin{array}{c}\text { PROCESSO DE } \\
\text { CLAUS }\end{array}$} & FUNDAMENTO & $\begin{array}{l}\text { Tal processo consiste na combustão de parte da corrente rica em sulfeto de } \\
\text { hidrogênio, liberada no processo "Alcanolamina", com um terço da } \\
\text { quantidade estequiométrica de ar necessária. } \mathrm{O} \mathrm{SO}_{2} \text { resultante dessa queima } \\
\text { reage com o } \mathrm{H}_{2} \mathrm{~S} \text { restante, na presença de um catalisador de alumina, a fim de } \\
\text { se produzir } \mathrm{S}^{\circ} \text {. } \\
2 \mathrm{H}_{2} \mathrm{~S}_{(\mathrm{g})}+\mathrm{SO}_{2(\mathrm{~g})} \rightarrow 3 \mathrm{~S}_{(\mathrm{s})}^{\circ}+2 \mathrm{H}_{2} \mathrm{O}_{(l)}\end{array}$ \\
\hline & VANTAGENS & $\begin{array}{l}\text { - Obtenção de um produto }\left(\mathrm{S}^{\circ}\right) \text { com interesse de mercado; } \\
\text { - Recuperação de enxofre de } 93 \text { a } 95 \% \text {; } \\
\text { - Pequeno impacto ambiental quando acoplado com uma unidade de } \\
\text { tratamento de gases residuais; } \\
\text {-Baixo consumo de produtos químicos; }\end{array}$ \\
\hline & DESVANTAGENS & $\begin{array}{l}\text { - Este processo se torna viável em locais com quantidades de remoção acima } \\
\text { de } 50 \text { ton./dia enxofre; } \\
\text { - Alto custo de instalação; }\end{array}$ \\
\hline & REFERÊNCIAS & $\begin{array}{l}\text { GUIMARÃES, } 2006 \\
\text { LI, } 2008 \\
\text { OPRIME, } 2001\end{array}$ \\
\hline \multirow{4}{*}{$\begin{array}{l}\text { ABSORÇÃO } \\
\text { (LAVADORES) }\end{array}$} & FUNDAMENTO & $\begin{array}{l}\text { Processo físico baseado na transferência dos poluentes presentes no gás } \\
\text { residual para uma fase líquida não-volátil. Trata-se de um dispositivo no qual } \\
\text { se realiza a separação de um poluente gasoso por Intermédio da lavagem do } \\
\text { mesmo com água que na maioria dos casos é nebulizada para formar } \\
\text { pequenas gotículas. A fase líquida contaminada resultante é usualmente } \\
\text { tratada biologicamente e recirculada para o lavador. }\end{array}$ \\
\hline & VANTAGENS & $\begin{array}{l}\text { - Custos de capital moderados; } \\
\text { - Custos operacionais moderados; } \\
\text { - Fácil operação; } \\
\text { - Podem operar com a presença de material particulado na corrente gasosa; } \\
\text { - Absorve } \mathrm{H}_{2} \mathrm{~S} \text { e } \mathrm{CO}_{2} ; \\
\text { - Ocupa pouco espaço; }\end{array}$ \\
\hline & DESVANTAGENS & $\begin{array}{l}\text { - Os poluentes são transferidos para uma nova fase ao invés de serem } \\
\text { destruídos; } \\
\text { - Somente aplicável para correntes gasosas moderadamente contaminadas; } \\
\text { - Não remove a maioria dos compostos orgânicos voláteis; } \\
\text { - Gasta uma quantidade significativa de água. }\end{array}$ \\
\hline & REFERÊNCIAS & REIJENGA et al., 2008 \\
\hline \multirow{4}{*}{$\begin{array}{l}\text { ABSORÇÃO } \\
\text { QUÍMICA POR } \\
\text { FERRO (III) }\end{array}$} & FUNDAMENTO & 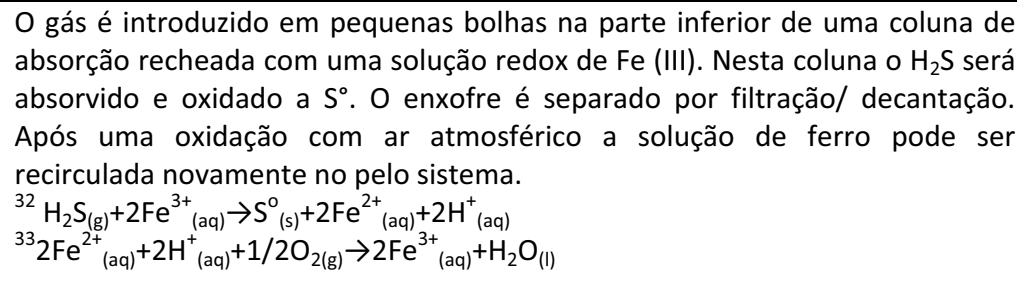 \\
\hline & VANTAGENS & $\begin{array}{l}\text { - Obtenção de enxofre elementar como produto principal }\left(\mathrm{S}^{\circ}\right) ; \\
\text { - Absorção regenerativa; } \\
\text { - Sistema de simples operação; } \\
\text { - Opera em temperatura ambiente; } \\
\text { - Baixos custos de instalação e manutenção; } \\
\text { - Seletivo para } \mathrm{H}_{2} \mathrm{~S} \text {; }\end{array}$ \\
\hline & DESVANTAGENS & $\begin{array}{l}\text { - Aplicado a baixas correntes gasosas; } \\
\text { - Custo moderado com manutenções para remover depósitos de enxofre; }\end{array}$ \\
\hline & REFERÊNCIAS & $\begin{array}{l}\text { GENDEL et al , } 2009 \\
\text { HORIKAWA et al, } 2004 \\
\text { MATTHÍASDÓTTIR, } 2006\end{array}$ \\
\hline
\end{tabular}

32 Absorção química do $\mathrm{H}_{2} \mathrm{~S}$;

33 Oxidação do $\mathrm{Fe}(\mathrm{II})$ a $\mathrm{Fe}(\mathrm{III})$. 
Continuação...

\begin{tabular}{|c|c|c|}
\hline \multirow{4}{*}{ INCINERAÇÃO } & FUNDAMENTO & $\begin{array}{l}\text { - Ocorre a combustão direta em tochas ("flare"). Se temperaturas } \\
\text { suficientemente elevadas não forem alcançadas a combustão dos poluentes } \\
\text { pode ser incompleta. }\end{array}$ \\
\hline & VANTAGENS & $\begin{array}{l}\text { - Custos de capital baixos; } \\
\text { - Custos operacionais baixos; } \\
\text { - Boa alternativa para a queima de biogás em pequenas estações de } \\
\text { tratamento; } \\
\text { - Possibilidade de aproveitamento da energia térmica gerada pela combustão. }\end{array}$ \\
\hline & DESVANTAGENS & $\begin{array}{l}\text { - A combustão incompleta pode resultar na geração de compostos sulfurados; } \\
\text { - Perda de potencial de energia quando o calor não é recuperado; } \\
\text { Técnica destrutiva; }\end{array}$ \\
\hline & REFERÊNCIAS & $\begin{array}{l}\text { LAM et al, } 2010 \\
\text { SCHIRMER, } 2008\end{array}$ \\
\hline \multirow{4}{*}{$\begin{array}{l}\text { SEPARAÇÃO } \\
\text { CRIOGÊNICA }\end{array}$} & FUNDAMENTO & $\begin{array}{l}\text { Os vapores são condensados e separados por resfriamento com temperaturas } \\
\text { próximas a } \\
-170^{\circ} \mathrm{C} \text { ou compressão em torno de } 80 \text { bar. Baseia-se nos diferentes pontos de } \\
\text { liquefação dos gases. Há nesse caso uma aproximação das moléculas ou a } \\
\text { redução da energia cinética. }\end{array}$ \\
\hline & VANTAGENS & $\begin{array}{l}\text { - Custo de capital moderado; } \\
\text { - Custos operacionais moderados; } \\
\text { - Não é necessário o uso de produtos químicos neste processo; } \\
\text { - Produto com elevada pureza; }\end{array}$ \\
\hline & DESVANTAGENS & $\begin{array}{l}\text { - Os poluentes são transferidos para uma nova fase ao invés de serem } \\
\text { destruídos; } \\
\text { - Elevado custo de manutenção por ser um processo composto por vários } \\
\text { compressores e resfriadores; } \\
\text { - Necessita de grande quantidade de água para as trocas térmicas. }\end{array}$ \\
\hline & REFERÊNCIAS & $\begin{array}{l}\text { REIJENGA et al., } 2008 \\
\text { CHERNICHARO et al, } 2010\end{array}$ \\
\hline \multirow{4}{*}{$\begin{array}{l}\text { PROCESSOS } \\
\text { BIOLÓGICOS }\end{array}$} & FUNDAMENTO & $\begin{array}{l}\text { Eles são classificados de acordo com a mobilidade da fase aquosa e da biomassa } \\
\text { no interior do reator biológico. } \\
\text { Biofiltro: Consiste na passagem de compostos voláteis biodegradáveis em } \\
\text { reatores contendo um meio suporte com micro-organismos imobilizados na } \\
\text { forma de biofilme. } \\
\text { Biopercolador: Se difere do biofiltro pela alimentação contínua de fase líquida } \\
\text { no topo de uma coluna também preenchida com material de enchimento } \\
\text { recoberto por um biofilme de micro-organismos. } \\
\text { Biolavador: é composto por uma coluna de absorção, onde os poluentes são } \\
\text { solubilizados em água. A fase líquida é transferida para um reator aerado } \\
\text { contendo micro-organismos que degradam os poluentes. A água, uma vez } \\
\text { regenerada é continuamente recirculada pelo topo da coluna. }\end{array}$ \\
\hline & VANTAGENS & $\begin{array}{l}\text { - Baixos custos de instalação; } \\
\text { - Bom contato entre o gás e o biofiltro; } \\
\text { - Contem boa área superficial; } \\
\text { - Operação simples; } \\
\text { - Redução satisfatória de odores. } \\
\text { - Baixo custo de Operação; } \\
\text { - Satisfatório para níveis moderados de contaminação; }\end{array}$ \\
\hline & DESVANTAGENS & $\begin{array}{l}\text { - Apropriados somente para o tratamento de baixas concentrações de } \\
\text { odorantes; } \\
\text { - Impossível controle do processo; } \\
\text { - Problemas com formação de caminhos preferenciais no meio suporte; } \\
\text { - Limitado controle de processo; } \\
\text {-Necessitam de uma disponibilização final da biomassa. }\end{array}$ \\
\hline & REFERÊNCIAS & $\begin{array}{l}\text { CHERNICHARO et al, } 2010 \\
\text { OPRIME, } 2001 \\
\text { PANTOJA FILHO, } 2008\end{array}$ \\
\hline
\end{tabular}




\section{CONSIDERAÇÕES FINAIS}

Alguns dos métodos revisados para o tratamento de sulfeto de hidrogênio emitido por reatores anaeróbio, do tipo UASB, tornam-se sofisticados e, muitas vezes inapropriados para a devida aplicação. Exemplo disso são os processos da Alcanolamina, de Claus, que somente se tornam viáveis em locais onde o tratamento diário seja acima de 50 ton. dia ${ }^{-1}$ de enxofre recuperado. Entretanto as emissões de sulfeto de hidrogênio em reatores anaeróbios, usualmente, não chegam a níveis muito elevados ( $0,4 \%$ do biogás emitido pelo UASB). A incineração é uma forma eficiente de remoção de odores em gases residuais, no entanto, não é um fim definitivo e apropriado sendo que, a combustão do sulfeto de hidrogênio gera dióxido de enxofre $\left(\mathrm{SO}_{2}\right)$, um gás fortemente poluente atmosférico associado a precipitações ácidas em regiões urbanas. As tecnologias de remediação de $\mathrm{H}_{2} \mathrm{~S}$ baseadas na filtração por micro-organismos são simples e possuem boa aplicabilidade em baixas concentrações gasosas, no entanto, não conseguem recuperar o enxofre. As tecnologias baseadas na adsorção física demonstram desvantagem por não serem, na maioria das vezes, de fácil regeneração. Deste modo o resíduo é transferido para uma nova fase, e esta deve ser encaminhada para um fim adequado, como é o caso de tecnologias que utilizam carvão ativado. $\mathrm{O}$ processo de absorção química de $\mathrm{H}_{2} \mathrm{~S}$ em soluções de Fe (III) oferece remoção seletiva e com alta eficiência do $\mathrm{H}_{2} \mathrm{~S}$ presente na corrente, associada a um baixo consumo de produtos químicos. A solução de Fe (III) funciona como pseudo-catalisador que pode ser facilmente regenerado por oxidação. Outro fator importante é a conversão de sulfeto de hidrogênio em enxofre elementar $\left(S^{\circ}\right)$, um composto passível de comercialização. Considerando que o tratamento do efluente gasoso deve ser sustentável e simples a implantação de sistemas de tratamento de sulfeto de hidrogênio em emissões odoríferas, o sistema pode ser concebido a partir da oxidação do enxofre com soluções de Fe (III).

\section{REFERÊNCIAS}

AGRAWAL, L.K.; HARADA, H.; OKUI, H. Treatment of dilute wastewater in a UASB reactor at a moderate temperature: Performance Aspects. Journal Of Fermentation And Bioengineering, Niigata, v. 83, n. 2, p.179-184, 1997.

ALIABAD, Z.H.; MIRZAEI, S. Removal of $\mathrm{CO}_{2}$ and $\mathrm{H}_{2} \mathrm{~S}$ using aqueous alkanolamine solusions. World Academy Of Science, Engineering And Technology: Engineering and Technology, Shahroud, Iran, p.194-203, 2009.

AMARAL, R. A. Remoção de $\mathrm{CO}_{2}$ e $\mathrm{H}_{2} \mathrm{~S}$ do Gás Natural por Contactores com Membranas. 2009 .117f. Dissertação (Mestrado em Engenharia Química)-UFRJ, Rio de Janeiro, 2009.

AROCA, $G$ et al. Comparison on the removal of hydrogen sulfide in biotrickling filters inoculated with Thiobacillus thioparus and Acidithiobacillus thiooxidans. Electronic Journal of Biotechnology, Valparaíso, p.514-520, 18 Apr. 2007.

CABRAL, F.A.S; BELLI, P. Tratamento de odores em digestor anaeróbio utilizando o processo de biofiltração. In: XXVIII CONGRESSO INTERAMERICANO DE INGENÍERIA SANITÁRIA Y AMBIENTAL, 2002, Cancun-México. Anais do XXVIII Congresso Interamericano de Ingeníaria 
Sanitária y Ambiental. Cancun, México: Associación Interamericana de Ingeníaria Sanitária y Ambiemtal, 2002.

CAMPOS, P.B. Avaliação do tratamento de sulfeto de hidrogênio através de fotocatálise. 2009. 55 f. Trabalho de Conclusão de Curso (Graduação)-Curso de Graduação em Engenharia Sanitária e Ambiental, Universidade Federal de Santa Catarina, Florianópolis, 2009.

CHERNICHARO, C.A.L. et al. Alternativas para o controle de emissões odorantes em reatores anaeróbios tratando esgoto doméstico. Nova Técnica, Belo Horizonte, p.229-236, set. 2010.

FISCHER, M.E. Biogas purification: $\mathrm{H}_{2} \mathrm{~S}$ removal using biofiltration. 2010. $138 \mathrm{f}$. Thesis (Master of Applied Science in Chemical Engineering) - University Of Waterloo, Waterloo, 2010.

FRARE, L.M.; GIMENES, M. L.; PEREIRA, N. C. Processo para remoção de ácido sulfídrico de biogás. Engenharia Sanitária Ambiental, Rio de Janeiro, v. 14, n. 2, p.167-172, 2009

GARCIA JUNIOR, O. Estudos da biolixiviação de minérios de urânio por Thiobacillus ferrooxidans. 1989. 276 f. Tese (Doutor em Ciências) - Unicamp, Campinas, 1989.

GENDEL, Y.; LEVI, N.; LAHAV, O. $\mathrm{H}_{2} \mathrm{~S}$ removal using a modified, Low-pH Liquid Redox Sulfur Recovery (LRSR): Process with electrochemical regeneration of the Fe catalyst couple. Environmental Science \& Technology, Israel, p.a-e, 23 set. 2009.

GLÓRIA, R.M. Estudo dos processos de formação, acumulação, emissão e oxidação de sulfeto de hidrogênio em reatores UASB tratando esgotos domésticos. 2009. 65 f. Dissertação (Curso de Saneamento, Meio Ambiente e Recursos Hídricos - Mestrado), UFMG, Belo Horizonte, 2009.

GREGORAKOS, L. et al. Hydrogen sulfide poisoning: management and complications. Angiology 4 6: p. 1123-1131, 1995.

GUIMARÃES, E.M. Causas e formas de corrosão na unidade de recuperação de enxofre da Refinaria Gabriel Passos (REGAP/PETROBRAS). 2006. 178 f. Dissertação (Curso de Pósgraduação em Engenharia Química- Mestrado) - UFMG, Belo Horizonte, 2006.

HORIKAWA, M.S. et al. Chemical absorption of $\mathrm{H}_{2} \mathrm{~S}$ for biogas purification. Brazilian Journal Of Chemical Engineering, Maringá, v. 21, n. 3, p.415-422, jul./set. 2004.

KLINKENBIJL, J.M.; DILLON M.L.; HEYMAN, E.C. Gas pre-treatment and their impact on liquefaction processes. Research \& Technology Centre Amsterdam, 1999.

KOHL, A.L.; RIESENFELD, F.C. Gas purification. 4 ed. - Ed. Gulf Pub. Co., Book Division, Houston, 1985.

LAM, Charles H. K. et al. Use of incineration MSW Ash: A review. Sustainability, Hong Kong, p.1943-1968, June 2010.

LEDUC, L.G.; FERRONI, G. D. The chemolithotrophic bacterium Thiobacillus ferrooxidans. FEMS Microbiology Reviews, v. 14, p. 103-120, 1994. 
$\mathrm{LI}, \mathrm{H}$. Selective catalytic oxidation of hydrogen sulfide from syngas. $100 \mathrm{f}$. Thesis (Master of Science) - University Of Pittsburgh, Pittsburgh, 2008.

MAAT, H.T.; HOGENDOORN, J.A.; VERSTEEG, G.f. The removal of hydrogen sulfide from gas streams using an aqueous metal sulfate absorbent. Part I. The absorption of hydrogen sulfide in metal sulfate solutions. Separation And Purification Technology, Netherlands, p.183-187, Oct. 2004.

MAINIER, F.B.; SANDRES, G.C.; TAVARES, S.S.M. Corrosão por sulfeto de hidrogênio $\left(\mathrm{H}_{2} \mathrm{~S}\right)$ e suas implicações no meio ambiente e na segurança industrial. In: CONGRESSO IBEROAMERICANO DE ENGENHARIA MECÂNICA, 8., 2007, Cuzco, Perú. Anais do 8o congresso iberoamericano de engenharia mecânica. Cuzco, 2007.

MARTIN, J.H. A new method to evaluate hydrogen sulfide removal from biogas. 2008. $87 \mathrm{f}$. Thesis (Master of Science)-Faculty Of North Carolina State University, Carolina do Norte, 2008.

MATTHÍASDÓTTIR, K.V. Removal of hydrogen sulfide from non-condensable geothermal gas at nesjavellir power plant. Department of Chemical Engineering, Lund Instituted of Technology, Lund, Sweden, 2006.

MILLS, B. Review of methods of odour control: Filtration and separation. Elsevier Science, Yardley, p.147-152, 23 jun. 1998.

OPRIME, M.E.A.G. Processo combinado químico-bacteriano para a remoção de $\mathrm{H}_{2} \mathrm{~S}$ de gases. 2001. 127 f. Tese (Curso de Biotecnologia- Doutorado) - UNESP, Araranguara, 2001.

OTTENGRAF, S.P.P et al. Biological elimination of volatile xenobiotic compounds in biofilters. Bioprocess Engineering. v. 1, p. 61-69, 1986.

PANTOJA FILHO, J.L.R. Avaliação da utilização de diferentes materias suporte na biofiltração do sulfeto de hidrogênio. 2008. 178 f. Dissertação (Mestre em Engenharia) - USP, São Carlos, 2008.

REIJENGA, J.C. et al. Comparing different biogas upgrading techniques. Eindhoven, $25 \mathrm{p}$, Eindhoven University of Technology, 2008.

ROCHA, A.P. Desempenho de filtro biológico na depuração e desodorização de sulfeto de hidrogênio. 2007. 135 f. Dissertação (Departamento de Hidráulica e Saneamento-Mestrado) -USP, São Carlos/SP, 2007.

ROCHA, et al. Introdução a química ambiental. 1 ed. Bookman, Porto Alegre, 2004, p. 85.

SCHIRMER, W.N. Tratamento de compostos orgânicos voláteis (COVs) em refinarias de petróleo: Principais tecnologias. In: VI SEMANA DE ESTUDOS DA ENGENHARIA AMBIENTAL, 2008, Campus de Irati.

SEINFELD, J.H. Air Pollution: physical and chemical fundamentals. New York: Mcgraw - Hill, Madrid- Espanha, 1975. 
SHAREEFDEEN, Z.M. Development of a biofilter media for removal of hydrogen sulphide. Global Nest Journal, Sharjah, v. 11, n. 2, p.218-222, 17 jan. 2009.

SILVA, A.B. Avaliação da produção de odor na estação de tratamento de esgoto Paranoá e seus problemas associados. 2007. 132 f. Dissertação (Mestre) -, UNB, Brasília, 2007.

SILVA, M.B. Influência do tipo de meio suporte no desempenho de biofiltros aplicados à remoção de $\mathrm{H}_{2} \mathrm{~S}$ do ar atmosférico em sistemas de esgoto sanitário. 2008. 156 f. Dissertação (Mestre em Engenharia Ambiental) - UFES, Vitória, 2008.

SOUZA, C.L. Estudo das rotas de formação, transporte e consumo dos gases metano e sulfeto de hidrogênio resultantes do tratamento de esgoto doméstico em reatores UASB. $147 \mathrm{f}$. Tese (Curso de Saneamento, Meio Ambiente e Recursos Hídricos- Doutor) -UFMG, Belo Horizonte, 2010.

SYED, M. et al. Removalof hydrogen sulfide from gas strems using biological processes- A review. Canadian Biosystems Enginering, vol. 48,2.1-2.14, 2006.

TACLA, R.M.B. Aproveitamento de resíduos industriais para a biofiltração do sulfeto de hidrogênio. 2004. 175 f. Dissertação (Mestre em Tecnologia de Alimentos) - Departamento de Engenharia Química, UFPR, Curitiba, 2004.

ZAMAN, J.; CHAKMA, A. Production of hydrogen and sulfur from hydrogen sulfide. Fuel Processing Technology, Alberta, Canadá, p.159-198, 1995. 